\title{
PENENTUAN PENGGUNAAN LAHAN GAMBUT UNTUK PENINGKATAN EKONOMI MASYARAKAT DI KABUPATEN INDRAGIRI HULU
}

\author{
Yelly Zamaya ${ }^{1}$ \\ Dahlan Tampubolon ${ }^{2}$ \\ Misdawita $^{3}$ \\ Ekonomi Pembangunan, Universitas Riau, Indonesia ${ }^{1,2}$ \\ ${ }^{1}$ Penulis Korespondensi e-mail: yelly.zamaya@lecturer.unri.ac.id
}

\begin{abstract}
Sustainable peatland management will have an impact on the welfare of the community as a whole. Rural communities use peatlands as their primary source of income. This article aims to formulate plants on peatlands to improve the economy of the community Indragiri Hulu Regency. The method used is a combination of field observation data and a participatory geographic information system (GIS-P). The utilization of peatlands is still dominated by oil palm and rubber plants. Peatlands have the potential for high-value and environmentally friendly vegetation, such as gaharu, barley and liberica coffee. The shallower peatlands are suitable for horticultural vegetation such as rice and short-lived vegetables and fruits. Besides, it is reasonable to cultivate wetlands in Indragiri Hulu, such as catfish, catfish, tilapia and tilapia. Through this participatory information system, it is possible to determine the commodities developed in the region.
\end{abstract}

Keywords : peatland, income, GIS-P, environmentally, commodities

\begin{abstract}
ABSTRAK
Pengelolaan lahan gambut yang berkelanjutan akan berdampak pada kesejahteraan masyarakat secara keseluruhan. Masyarakat pedesaan menggunakan lahan gambut sebagai sumber pendapatan utama mereka. Artikel ini bertujuan untuk merumuskan tumbuhan di lahan gambut untuk meningkatkan perekonomian masyarakat Kabupaten Indragiri Hulu. Metode yang digunakan adalah kombinasi data observasi lapangan dan sistem informasi geografi partisipatif (SIG-P). Pemanfaatan lahan gambut masih didominasi oleh tanaman kelapa sawit dan karet. Lahan gambut memiliki potensi vegetasi bernilai tinggi dan ramah lingkungan, seperti gaharu, barley, dan kopi liberika. Lahan gambut yang lebih dangkal cocok untuk tumbuh-tumbuhan hortikultura seperti padi dan sayur mayur serta buahbuahan berumur pendek. Selain itu lahan basah di Indragiri Hulu layak dibudidayakan, seperti lele, lele, nila dan nila. Melalui sistem informasi partisipatif ini, sangat memungkinkan untuk menentukan komoditas yang dikembangkan di daerah.
\end{abstract}

Kata Kunci : lahan gambut, pendapatan, SIG-P-P, lingkungan, komoditas 


\section{PENDAHULUAN}

Pengelolaan lahan gambut memiliki dilema tersendiri antara pemenuhan kebutuhan masyarakat dan kelestarian lahan gambut. Jumlah penduduk yang terus meningkat memaksa manusia harus memenuhi kebutuhan primernya berupa makanan, pakaian dan tempat tinggal di wilayahnya berada. Dari berbagai studi yang sudah dilakukan terjadi kontradiksi antara pemenuhan kebutuhan primer masyarakat dengan keberlangsungan ekosistem gambut. Penggunaan lahan gambut tetapi dengan tidak memperhatikan karakteristik khas dari gambut itu sendiri maka membuat lahan gambut terdegradasi (Masganti et al., 2014).

Lahan gambut sebagai ekosistem lahan basah esensial terbentuk tanah gambut dengan lapisan organik yang membusuk (Page \& Baird, 2016) dalam kondisi tergenang air dan kekurangan oksigen (Cole et al., 2015). Ekosistemnya yang unik dengan sistem hidrologi yang kompleks memiliki peran penting sebagai penyedia jasa ekosistem seperti penyerapan dan penyimpanan karbon, perlindungan keanekaragaman hayati (Cole et al., 2015; Stephanie et al., 2017).

Berdasarkan data lahan basah global tahun 2019, Indonesia memiliki ekosistem gambut terbesar kedua di dunia, dengan luas wilayah 22,5 juta hektar (ha). Provinsi dengan luas wilayah terluas adalah Papua dengan luas wilayah 6,3 juta ha. Disusul Kalimantan Tengah (2,7 juta ha), Riau (2,2 juta ha), Kalimantan Barat (1,8 juta ha) dan Sumatera Selatan (1,7 juta ha). Selain itu, Papua Barat memiliki 1,3 juta ha lahan gambut, Kalimantan Timur memiliki 0,9 juta ha dan Kalimantan Utara, Sumatera Utara, dan Kalimantan Selatan masing-masing 0,6 juta ha.

Produksi dan produktivitas tanaman dapat ditingkatkan dengan mengoptimalkan lahan gambut yang telah direklamasi dan ditinggalkan. Pengelolaan air yang lebih baik dengan membangun dan merevitalisasi prasarana yang ada, terutama sistem drainase dan pengatur air maka akan meningkatkan hasil panen. Produktivitas lahan juga dapat ditingkatkan dengan diversifikasi tanaman, ikan dan unggas. Hasil studi selama lebih dari 60 tahun menunjukkan pentingnya melibatkan masyarakat lokal dalam pengembangan dan pengelolaan lahan gambut dengan tidak meninggalkan kearifan lokal. Untuk keberlangsungan pengelolaan dan pengembangan lahan gambut harus fokus pada revitalisasi jaringan drainase yang ada (Sulaiman et al., 2019).

Populasi penduduk di dunia akan terus bertambah, diperkirakan pada tahun 2050 akan meningkat lebih dari $35 \%$. Untuk dapat memenuhi kebutuhan pangan populasi penduduk yang 
terus berkembang ini, maka produksi tanaman perlu berlipat ganda (Roberts \& Mattoo, 2018). Di Indonesia sendiri persaingan kepentingan mempengaruhi ketahanan pangan (Neilson \& Wright, 2017). Saat ini hutan dan lahan gambut Indonesia banyak dikonversi untuk keperluan pertanian dan perkebunan khususnya untuk kelapa sawit, akasia dan karet. Dengan peralihan lahan tersebut, fungsi awal hutan dan lahan gambut sebagai konservasi keanekaragaman hayati dan cadangan karbon berubah menjadi salah satu faktor produksi komoditas pertanian. Konversi hutan rawa gambut alami tertinggi terjadi di Sumatera (Uda et al., 2017).

Provinsi Riau merupakan provinsi kedua yang memiliki lahan gambut terluas di Indonesia, dimana luas lahan gambutnya adalah 3.864.414 Ha atau 60,1\% dari lahan gambut yang ada di pulau Sumatera. Dengan estimasi ketebalan gambut kurang dari $300 \mathrm{~cm}$ seluas 1.417.762 $\mathrm{Ha}(36,7 \%)$ dan ketebalan lebih dari $300 \mathrm{~cm}$ adalah 2.449.652 $\mathrm{Ha}$ (63,3\%) (Wahyunto et al., 2003). Pembukaan lahan gambut dengan cara membakar merupakan cara yang sangat tradisional dan berbiaya murah yang berdampak pada kerusakan lingkungan dan berdampak terhadap kesehatan masyakarat. Sebagai gambaran pada tahun 2015 terjadi bencana asap yang parah di Provinsi Riau, dimana terjadi kehilangan hutan dan lahan mencapai 500.000 hektare dan pada tahun 2019 dengan hutan dan lahan terbakar mencapai 300.000 hektare. Baru-baru ini, ekspansi cepat pertanian komersial dan perkebunan industri menciptakan tekanan kuat pada lahan gambut Indonesia Pembukaan lahan gambut menyebabkan gambut mengering karena tidak lagi dapat menyerap air dan menjadi lebih rentan terhadap kebakaran (Miettinen et al., 2016; Turetsky et al., 2015).

Meskipun beberapa proyek restorasi lahan gambut telah dimulai dan bergerak maju, rencana tersebut sangat kekurangan dana (Hansson \& Dargusch, 2017) dan hanya mencapai 5 persen dari target pada 2018. Akibatnya bencana asap kerap muncul terutama di bulan-bulan dengan curah hujan rendah ( $<100 \mathrm{~mm} /$ bulan), yaitu Februari - Maret dan Juni - Agustus. Pemicu bencana ini adalah kegiatan pembakaran biomassa tumbuhan dalam rangka penyiapan lahan untuk kebun ataupun perkebunan. Meskipun sebenarnya kegiatan ini sudah dilarang pemerintah melalui pemberlakukan UU No. 32/2009 dan diperkuat dengan Peraturan Pemerintah No. 71 Tahun 2014, lemahnya pengawasan masih memungkinkan hal ini dilakukan secara sembunyisembunyi dan pada saat-saat tertentu api sangat sulit dikendalikan sehingga membakar lingkungan sekeliling. 
Gambut di Provinsi Riau dibentuk oleh akumulasi residu vegetasi tropis yang banyak mengandung lignin dan nitrogen. Sifat gambut yang tidak bisa kembali lagi seperti semula karena adanya pengeringan, memerlukan suatu pengembangan keilmuan yang seimbang agar meminimalkan dampak lingkungan, dan pengaturan air sehingga mengurangi risiko kebakaran. Hal-hal yang harus diperhatikan dalam pengelolaan lahan gambut adalah melihat karakteristik lahan, lanskap dan desain penggunaan lahan, serta pengembangan komunitas masyarakat lahan gambut (Sulaiman et al., 2019).

Pemanfaatan lahan gambut untuk sektor pertanian sangat ditentukan oleh sifat pengairan/drainase, daya dukung tanaman, ketebalan dan tingkat kematangan dan sifat kimia yang berubah menyesuaikan dengan bentuk lahan, sehingga potensi dan pengembangannya tentu mengikuti pola tersebut. Dilihat dari sifat tersebut, lahan gambut umumnya lebih sesuai untuk tanaman yang memiliki masa tanam lama (tahunan) dari pada tanaman pangan dan hortikultura, sayuran dan buah-buahan semusim (Syahza et al., 2020).

Komoditi unggulan masyarakat pesisir yaitu pertanian, Kelapa, karet, kelapa sawit, sagu, kopi, kakao, pinang. Oleh karena itu, diperlukan pemahaman tentang pemanfaatan lahan gambut. Hal ini untuk mencegah kerusakan ekosistem gambut, menjaga keanekaragaman hayati, menyimpan karbon, menghasilkan oksigen, dan mengelola air. Kebijakan dan strategi pengelolaan ekosistem gambut dilakukan melalui pengembangan sosial ekonomi dan budaya masyarakat untuk mewujudkan kesejahteraan masyarakat berdasarkan kearifan lokal. Pengelolaan dan pemanfaatan lahan gambut telah berkontribusi pada perekonomian, bahkan sebagai sumber mata pencaharian utama masyarakat pesisir. Pemanfaatan lahan gambut yang berbasis kearifan lokal dapat menjaga kelestarian ekosistem gambut.

Pemanfaatan dan pengembangan lahan gambut pada saat ini selalu menjadi perdebatan. Perbedaan pandangan tentang pemanfaatan lahan gambut terbagi menjadi dua aspek kepentingan, yaitu aspek kepentingan lingkungan dan aspek kepentingan pengembangan lahan gambut untuk pertanian komoditi strategis. Saat ini berkembang pemahaman bahwa untuk pemanfaatan lahan gambut dimulai dengan pembukaan hutan/lahan gambut yang dominan menimbulkan masalah lingkungan yaitu berubahnya fungsi ekosistem gambut dan berdampak negatif ke masyarakat sekitar. Lahan gambut yang hendak dimanfaatkan oleh masyarakat sebelumnya dilakukan drainase dengan membuat kanal disekitar lahan tesebut. Tujuan dari pembuatan kanal ini adalah untuk mengurangi kondisi jenuh air pada lapisan perakaran tanaman 
yang mengakibatkan lahan gambut menjadi kering dan tidak lagi menyimpan air sehingga terjadi penurunan permukaan gambut dan amblas.

Kondisi tersebut mengharuskan para pihak yang berkepentingan mencari solusi agar keseimbangan antar dua kepentingan tersebut dapat tercapai, diantaranya melalui pengembangan pertanian berbasis partisipasi masyarakat dan kesesuaian lahan (pengembangan lahan gambut berkelanjutan). Terkait dengan penggunaan lahan untuk pertanian, maupun untuk sektor yang lainnya maka penerapan teknologi dan kebijakannya harus disesuaikan dengan kondisi lingkungan agar manfaat lahan dan hasil dari pertanian menjadi optimal dan dapat meningkatkan kesejahteraan masyarakat. Salah satu permasalahan yang terjadi pada lahan gambut yang berakibat pada kerusakan fungsi ekosistem gambut adalah kurang tepatnya adalam pemilihan komoditas atau sektor ekonomi yang dikembangkan di lahan tersebut. Dalam sektor pertanian, komoditas yang tidak sesuai dengan karakteristik lahan gambut dan terjadinya pengurasan air gambut berakibat pada kekeringan sehingga memicu kebakaran lahan.

Kabupaten Indragiri Hulu merupakan salah satu daerah di Provinsi Riau yang memiliki lahan gambut. Dari pengamatan penulis, di daerah tersebut belum dikembangkan secara optimal komoditi yang memiliki nilai ekonomi tinggi serta yang dapat menjaga ekosistem gambut. Untuk itu diperlukan suatu analisis tentang strategi pengembangan ekonomi masyarakat lahan gambut yang mana berfokus pada pengembangan komoditi agar dapat memberikan hasil produksi optimal bagi pembangunan daerah dan pengelolaan lahan gambut demi menjaga kelestariannya. Aspek utama dari pengelolaan lahan gambut adalah pengetahuan dan pengalaman dari semua pihak yang berkepentingan (Pramudya et al., 2020).

\section{METODOLOGI}

Kerangka kerja studi ini mengkombinasikan data pengamatan lapangan dengan sistem informasi geografis partisipatif atau SIG-Parsipatif sebagai pendekatan keilmuan untuk membantu pengembangan masyarakat dalam bidang ekonomi dengan menyeimbangkan kebutuhan masyarakat dan kelestarian lingkungan hidup. Metode ini memperkaya perencanaan tata ruang kabupaten atau wilayah dan akan sangat efektif jika mendapatkan komitmen politik dari pihak berwenang dan dukungan dari masyarakat. Pemetaan rinci lebih lanjut di tingkat kecamatan diperlukan untuk memvisualisasikan batas-batas fisik dari lahan gambut dan pengelolaan kawasan masyarakat dan memasukkannya ke dalam perencanaan pengelolaan 
lahan gambut yang terperinci. Selain itu, untuk menerapkan pendekatan ini, harus mendapatkan dukungan dari pemerintah (Sulistyawan et al., 2018).

Aplikasi SIG-Parsipatif untuk pemetaan jasa ekosistem terutama digunakan untuk menentukan wilayah penyediaan dan jasa budaya (Brown \& Fagerholm, 2015). SIG-Parsipatif juga berfungsi sebagai pendekatan yang inovatif untuk pengelolaan dan pemulihan suatu area (Garcia-Ayllon, 2019). Data yang digunakan adalah data sekunder yang berasal dari institusi terkait dan hasil dari pengamatan penulis di lapangan.

\section{HASIL DAN PEMBAHASAN}

Kabupaten Indragiri Hulu termasuk dalam Kesatuan Hidrologis Gambut (KHG) Badan Restorasi Gambut (BRG) Republik Indonesia, yaitu KHG Sungai Indragiri - Sungai Cenaku yang memiliki luas $18.470 \mathrm{Ha}$. Mata pencaharian masyarakat di kawasan ekosistem gambut Kabupaten Indragiri Hulu mayoritas bergerak pada sektor pertanian (pertanian, perkebunan dan perikanan). Berdasarkan data yang didapat dari Badan Pusat Statistik (BPS) Indragiri Hulu tahun 2020 sektor usaha yang mendominasi pertumbuhan ekonomi adalah sektor Jasa Kesehatan dan Kegiatan Sosial, Informasi dan Komunikasi dan Pertanian, Kehutanan dan Perikanan. Berikut tabel laju pertumbuhan Produk Domestik Regional Bruto (PDRB) Kabupaten Indragiri Hulu. 
Tabel 1. Laju Pertumbuhan Produk Domestik Regional Bruto Atas Dasar Harga Konstan 2010 Menurut Lapangan Usaha di Kabupaten Indragiri Hulu (persen)

\begin{tabular}{clcc}
\hline & \multicolumn{1}{c}{ Lapangan Usaha } & \multicolumn{2}{c}{ Tahun } \\
\cline { 3 - 4 } & & 2019 & 2020 \\
\hline A & Pertanian, Kehutanan, dan Perikanan & 4,11 & 4,81 \\
B & Pertambangan dan Penggalian & $-0,94$ & $-2,66$ \\
C & Industri Pengolahan & 4,49 & 1,07 \\
D & Pengadaan Listrik dan Gas & 3,82 & 3,88 \\
E & Pengadaan Air, Pengelolaan Sampah, Limbah dan Daur Ulang & 1,66 & 2,32 \\
F & Konstruksi & 3,91 & $-3,10$ \\
G & Perdagangan Besar dan Eceran; Reparasi Mobil dan Sepeda & 4,59 & $-8,94$ \\
& Motor & & \\
H & Transportasi dan Pergudangan & 2,73 & $-18,54$ \\
I & Penyediaan Akomodasi dan Makan Minum & 4,74 & $-21,46$ \\
J & Informasi dan Komunikasi & 7,43 & 8,87 \\
K & Pertambangan dan Penggalian & 0,56 & 3,49 \\
L & Real Estat & 3,09 & 1,73 \\
M,N & Jasa Perusahaan & 5,61 & $-22,04$ \\
O & Administrasi Pemerintahan, Pertahanan dan Jaminan Sosial & 1,06 & $-1,45$ \\
& Wajib & & \\
P & Jasa Pendidikan & 5,27 & 1,89 \\
Q & Jasa Kesehatan dan Kegiatan Sosial & 9,52 & 11,26 \\
R,S,T,U & Jasa lainnya & 7,12 & $-17,52$ \\
& PDRB & 3,78 & $-0,12$ \\
\hline
\end{tabular}

Sumber : Indragiri Hulu Dalam Angka 2020, BPS

Kawasan gambut memberikan banyak manfaat bagi masyarakat lokal, misalnya berperan penting dalam menyimpan dan mengendalikan air hujan dan aliran permukaan. Ini meminimalkan bahaya banjir pada musim hujan. Pengelolaan lahan gambut yang berkelanjutan akan berdampak pada kesejahteraan masyarakat secara keseluruhan. Pengelolaan ekosistem berbasis kearifan lokal dan kesejahteraan masyarakat perlu difokuskan pada strategi pembangunan sosial ekonomi dan budaya. Tujuan keseluruhan dari pengelolaan habitat adalah untuk meningkatkan kesejahteraan masyarakat yang tinggal di kawasan lahan gambut. Pemanfaatan ekosistem ini oleh masyarakat di Kabupaten Indragiri Hulu telah memberikan kontribusi ekonomi baik secara regional maupun nasional. Hal ini terutama terjadi pada masyarakat pedesaan, yang menggunakan tanah sebagai sumber pendapatan utama mereka.

Berdasarkan dari peta yang dirilis oleh Badan Restorasi Gambut (BRG) pada laman Pranata Informasi Restorasi Ekosistem Gambut (PRIMS), maka kecamatan-kecamatan di Kabupaten Indragiri Hulu yang memiliki lahan gambut adalah Kecamatan Rengat, Rengat 
Barat, Kuala Cenaku dan Batang Gansal. Adapun luasan lahannya dapat dilihat pada gambar dibawah ini :

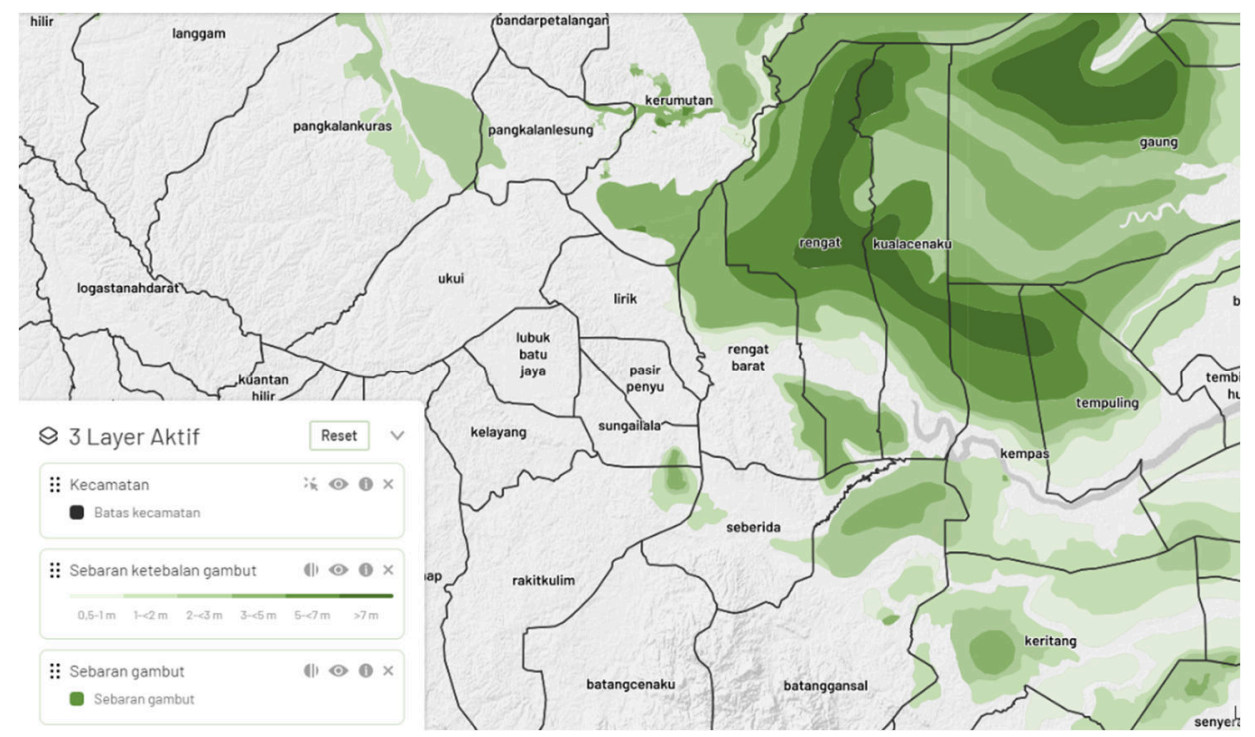

Gambar 1. Sebaran Lahan Gambut di Kabupaten Indragiri Hulu

Sumber : PRIMS, BRG 2021

Sebagaimana dilihat pada gambar diatas Kecamatan Kuala Cenaku dan Rengat mayoritas ditutupi oleh lahan gambut, sedangkan untuk Kecamatan Rengat Barat dan Batang Gansal juga memiliki lahan gambut, namun hanya sebagian. Berdasarkan ketebalan gambutnya Kecamatan Rengat dan Kuala Cenaku memiliki ketebalan gambut yang melebihi 700 cm. Pada lahan gambut yang ada di 4 (empat) kecamatan tersebut memiliki kedalaman yang bervariasi. Dimulai dari kedalaman kurang dari $50 \mathrm{~cm}$ sampai lebih dari $700 \mathrm{~cm}$. Gambut yang memiliki ketebalan lebih dari 300 meter memiliki fungsi lindung, yang artinya tidak boleh digunakan untuk budidaya (fungsi budidaya) karena kesuburan lahan gambut yang baik untuk pertanian adalah kedalaman kurang dari $200 \mathrm{~cm}$ (Nasrul, 2015).

Mayoritas lahan gambut di Kabupaten Indragiri Hulu digunakan untuk pertanian dan perkebunan. Berikut tabel luas lahan perkebunan menurut jenis tanaman.

Tabel 2. Luas Lahan Perkebunan Menurut Jenis Tanaman Per Kecamatan Lahan Gambut Kabupaten Indragiri Hulu (ha) Tahun 2020

\begin{tabular}{llccccc}
\hline No & Kecamatan & Kelapa Sawit & Kelapa & Karet & Kopi & Kakao \\
\hline 1 & Rengat & 1.232 & 151 & 882 & 55 & 51 \\
2 & Rengat Barat & 1.680 & 83 & 3.167 & 36 & 32 \\
3 & Batang Gansal & 7.055 & 484 & 644 & 8 & 40 \\
4 & Kuala Cenaku & 1.681 & - & 5.149 & - & 238 \\
\hline
\end{tabular}

Sumber : Indragiri Hulu Dalam Angka 2020, BPS 
Komoditi yang mendominasi perkebunan pada lahan gambut adalah karet dan kelapa sawit. Selain itu ada juga tanaman palawija dan buah-buahan yang ditanam di lahan gambut tersebut akan tetapi belum dikembangkan dengan optimal oleh masyarakat karena tidak memiliki nilai ekonomi atau nilai jual yang tinggi.

Tabel 3. Produksi Perkebunan Menurut Jenis Tanaman Per Kecamatan Lahan Gambut Kabupaten Indragiri Hulu (ton) Tahun 2020

\begin{tabular}{llccccc}
\hline No & Kecamatan & Kelapa Sawit & Kelapa & Karet & Kopi & Kakao \\
\hline 1 & Rengat & 3.898 & 26 & 1.205 & 11 & 33 \\
2 & Rengat Barat & 7.232 & 34 & 5.256 & 11 & 15 \\
3 & Batang Gansal & 30.912 & 156 & 933 & - & 21 \\
4 & Kuala Cenaku & 4.866 & - & 194 & - & 82 \\
\hline
\end{tabular}

Sumber : Indragiri Hulu Dalam Angka 2020, BPS

Kelapa sawit masih menjadi primadona bagi masyarakat yang memiliki lahan untuk menghasilkan pendapatan karena memiliki nilai jual yang menjanjikan. Harga Tandan Buah Segar (TBS) Kelapa Sawit, harga CPO dan harga kernel periode Maret 2021 disajikan pada tabel berikut :

Tabel 4. Harga TBS, CPO dan Kernel Kepala Sawit per Kilogram Maret 2021

\begin{tabular}{cc}
\hline Umur Kelapa Sawit & Harga TBS / Kg (Rp) \\
\hline 3 Tahun & $1.706,93$ \\
4 Tahun & $1.843,86$ \\
5 Tahun & $2.009,73$ \\
6 Tahun & $2.057,29$ \\
7 Tahun & $2.137,51$ \\
8 Tahun & $2.195,91$ \\
9 Tahun & $2.245,88$ \\
10 - 20 Tahun & $2.297,14$ \\
21 Tahun & $2.202,54$ \\
22 Tahun & $2.191,83$ \\
23 Tahun & $2.182,91$ \\
24 Tahun & $2.093,67$ \\
25 Tahun & $2.044,58$ \\
Harga Kernel & $9.976,89$ \\
Harga CPO (Crude Palm Oil) & $7.143,36$ \\
\hline
\end{tabular}

Sumber : Dinas Perkebunan Provinsi Riau, 2021

Harga TBS yang tertera pada tabel diatas ditentukan oleh pemerintah bekerjasama bersama petani dan perusahaan kelapa sawit dengan mempertimbangkan harga minyak mentah dunia dan berlaku untuk pembelian pada kebun plasma. Sedangkan untuk kebun swadaya yang 
dikelola oleh petani sendiri tergantung kesepakatan perusahaan dengan pemilik TBS. sebagaimana diketahui bersama kelapa sawit tidak ramah gambut karena menyerap air dan unsur hara tanah secara berlebihan sehingga dapat merusak ekosistem gambut.

Inovasi dalam bidang pertanian dan perkebunan harus dilakukan oleh masyarakat lahan gambut di 4 (empat) kecamatan di Kabupaten Indragiri Hulu tersebut, yaitu Kecamatan Rengat, Rengat Barat, Kuala Cenaku dan Batang Gansal. Tujuan dilakukannya inovasi adalah untuk menjaga kelestarian lahan gambut tetapi tetap dapat memenuhi kebutuhan ekonomi. Inovasi tersebut adalah memunculkan komoditi-komoditi yang berpotensi menjadi unggulan pada lahan gambut karena tetap dapat menjaga ekosistem dan bernilai tinggi, sebab hal ini mempertimbangkan kesesuaian lahan dengan komoditas yang dikembangkan.

Klau (2019) menentukan sebaran daerah agropolitan menggunakan nilai produksi tetapi kurang mempertimbangkan adanya kaitan dengan kesesuaian lahan dan daerah sekitar. Kesesuaian lokasi bisa memudahkan penetapan wilayah yang akan dikembangkan sebagai pusat agropolitan. Sedangkan Novitasari dan Ayuningtyas (2018) mengidentifikasi identifikasi produk yang akan dikembangkan di kecamatan tidak detail pada desa dan komoditasnya dan Jauhari (2020) menggunakan analisis hotspot dalam menentukan komoditas unggulannya.

Dalam penelitian ini didapat hasil skema pengembangan ekonomi masyarakat lahan gambut yang tertuang pada tabel dibawah ini :

Tabel 5. Skema Pengembangan Ekonomi Masyarakat Lahan Gambut berdasarkan SIGPartisipatif Di Kabupaten Indragiri Hulu

\begin{tabular}{|c|c|c|c|c|}
\hline Kecamatan & $\begin{array}{c}\text { Kedalaman } \\
\text { Lahan Gambut }\end{array}$ & $\begin{array}{c}\text { Kegiatan } \\
\text { Ekonomi } \\
\text { Masyarakat Saat } \\
\text { ini }\end{array}$ & $\begin{array}{c}\text { Pengembangan } \\
\text { Kegiatan Ekonomi } \\
\text { potensial di lahan } \\
\text { gambut }\end{array}$ & $\begin{array}{c}\text { Hal yang harus } \\
\text { dilakukan untuk } \\
\text { pengembangan } \\
\text { ekonomi masyarakat } \\
\text { ramah rambut }\end{array}$ \\
\hline Rengat & $100->700 \mathrm{~cm}$ & $\begin{array}{l}\text { 1. Pertanian } \\
\text { (jagung, cabe, } \\
\text { pisang, } \\
\text { rambutan) } \\
\text { 2. Usaha } \\
\text { Penggalian dan } \\
\text { Pertambangan } \\
\text { (pasir) } \\
\text { 3. Usaha } \\
\text { Perbengkelan } \\
\text { dan Perbaikan } \\
\text { 4. Usaha } \\
\text { Perdagangan }\end{array}$ & $\begin{array}{l}\text { Penanaman } \\
\text { vegetasi yang } \\
\text { bernilai jual tinggi : } \\
\text { 1. Gaharu } \\
\text { 2. Kayu } \\
\text { Geronggang } \\
\text { 3. Kopi Liberika }\end{array}$ & $\begin{array}{l}\text { 1. Lahan gambut } \\
\text { harus selalu } \\
\text { ditutupi dengan } \\
\text { tanaman atau } \\
\text { vegetasi yang } \\
\text { memiliki nilai } \\
\text { ekonomi tinggi } \\
\text { 2. Memanfaatkan } \\
\text { lahan gambut yang } \\
\text { terdegradasi }\end{array}$ \\
\hline
\end{tabular}




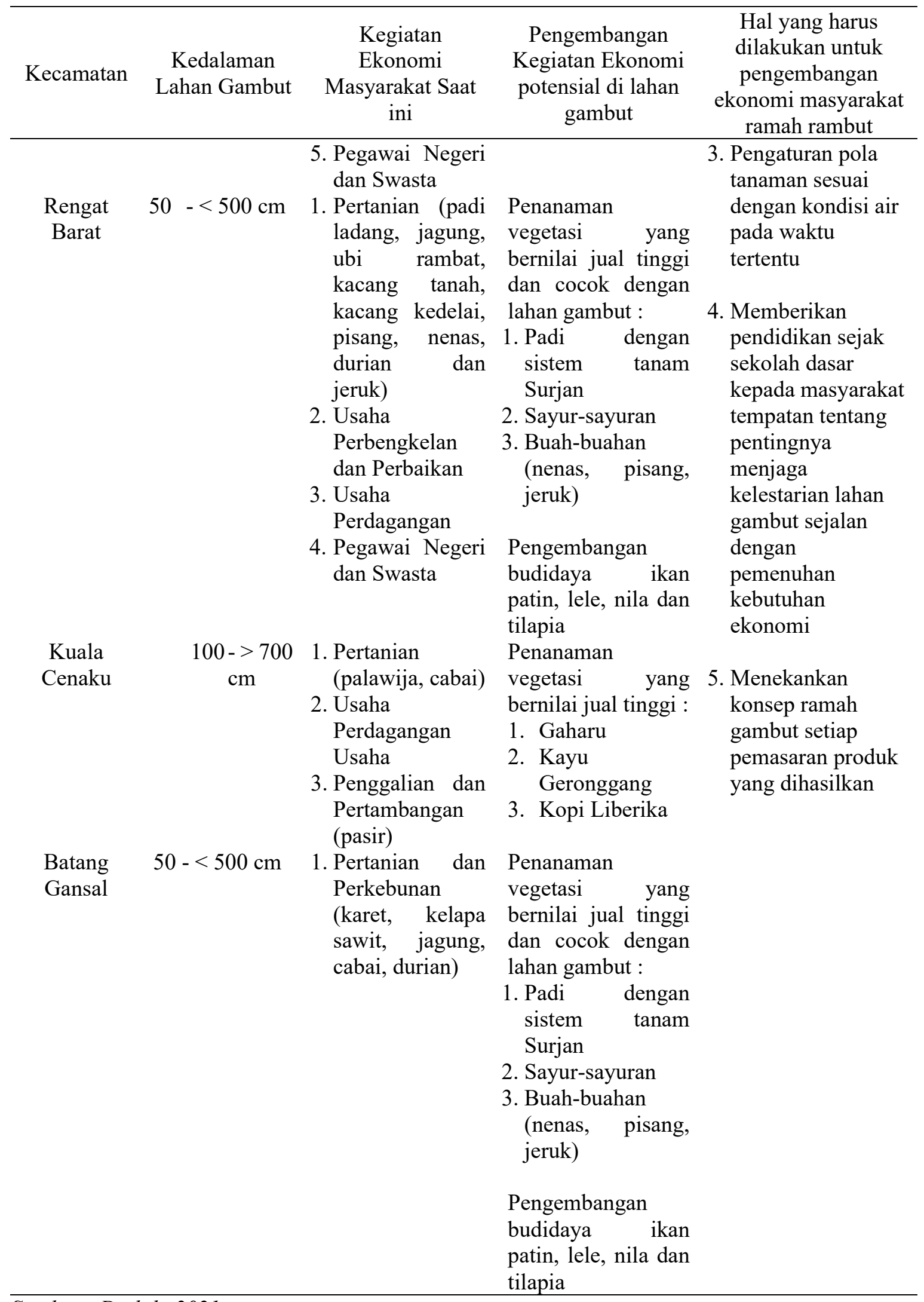

Sumber : Diolah, 2021 
Kecamatan Rengat dikenal sebagai sentra pembuat keripik pisang dan kerupuk bawang, namun masih belum bisa dilakukan perdagangan secara optimal karena keterbatasan bahan baku dan pemasaran. Saat ini baru mampu untuk mencukupi kebutuhan dalam kecamatan saja. Untuk itu perlu pengembangan sentra industri ini karena selain ciri khas daerah, dapat meningkatkan pendapatan masyarakat. Informasi dari Dinas Perindustrian dan Perdagangan Kabupaten Indragiri Hulu pada tahun 2019 menyatakan bahwa akan dibentuknya SIKIM (Sentra Industri Kecil dan Industri Menengah) Keripik Pisang dan Kerupuk Bawang yang berpusat di Rantau Mapesai Kecamatan Rengat. Namun SIKIM ini masih belum bisa dilaksanakan karena perlunya kajian mendalam dimulai hulu hingga hilir industri ini.

Pisang sebagai bahan baku utama pembuatan keripik pisang merupakan tanaman yang dapat tumbuh dengan baik di lahan gambut dengan kedalaman $<50-100 \mathrm{~cm}$. Pisang cocok untuk ditanam di Kecamatan Rengat Barat dan Batang Gansal. Tentu hal ini dapat menjadi sinergi antar kecamatan di Kabupaten Indragiri Hulu untuk mengembangkan industri yang berbahan baku pisang. Jika tanaman pisang dari berbagai varietas sesuai kebutuhan industri dapat dikembangkan dengan baik, maka akan bisa menjadi komoditi unggulan daerah. Pisang dapat memenuhi kebutuhan industri keripik pisang dan industri lainnya seperti tepung pisang, olahan pisang lainnya yang memerlukan kajian dan penelitian yang lebih lanjut.

Strategi pemberdayaan masyarakat dalam upaya perlindungan ekosistem gambut antara lain: 1) Mendorong pembangunan sosial masyarakat yang melakukan budidaya, khususnya pada subsektor perkebunan dan perkebunan industri; 2) Menjamin kelestarian kearifan lokal di masyarakat; dan 3) Merekomendasikan kepada pemerintah daerah untuk mengeluarkan kebijakan terkait pemanfaatan lahan gambut dengan cara yang menjaga keseimbangan lingkungan dan pembangunan berkelanjutan yang berlandaskan kearifan lokal. Dalam hal strategi kebijakan, alih teknologi pertanian yang adaptif dengan karakteristik unik ekosistem gambut harus menjadi target utama. Ini perlu dipadukan dengan membangun sistem kelembagaan petani yang kuat, menyediakan akses ke sistem permodalan petani lokal, dan mengembangkan sistem budidaya dengan meningkatkan pengetahuan masyarakat lokal. 


\section{KESIMPULAN DAN SARAN}

Studi di Kabupaten Indragiri Hulu Provinsi Riau mendapati sektor pertanian terus tumbuh di saat ekonomi mengalami penurunan. Tanaman kelapa sawit dan karet masih mendominasi pemanfaatan lahan untuk pertanian. Melalui pengamatan dan pemanfaatan sistem informasi geografis didapatkan pada lahan gambut cocok untuk tanaman benilai ekonomis tinggi, seperti gaharu, kayu geronggang dan kopi Liberika dan tanaman hortikultura padi, sayuran dan buah-buahan yang umur pendek. Selain itu Budidaya ikan di lahan basah cocok untuk dilakukan di Kabupaten Indragiri Hulu seperti ikan patin, lele, nila dan tilapia. Melalui sistem informasi yang partisipatif ini bisa ditentukan wilayah yang akan dikembangkan secara lengkap.

\section{DAFTAR PUSTAKA}

Brown, G., \& Fagerholm, N. (2015). Empirical PPGIS/PGIS mapping of ecosystem services: a review and evaluation. Ecosystem Services, 13, 119-133. https://doi.org/10.1016/j.ecoser.2014.10.007

Castro-Arce, K., \& Vanclay, F. (2020). Transformative social innovation for sustainable rural development: An analytical framework to assist community-based initiatives. Journal of Rural Studies. https://doi.org/10.1016/j.jrurstud.2019.11.010

Cole, L. E. S., Bhagwat, S. A., \& Willis, K. . (2015). Long-term disturbance dynamics and resilience of tropical peat swamp forests. Journal of Ecology, 103, 16-30. https://doi.org/10.1111/1365-2745.12329

Cooper, H. V., Vane, C. H., Evers, S., Aplin, P., Girkin, N. T., \& Sjögersten, S. (2019). From peat swamp forest to oil palm plantations: The stability of tropical peatland carbon. Geoderma. https://doi.org/10.1016/j.geoderma.2019.02.021

Dargie, G. C., Lewis, S. L., Lawson, I. T., Mitchard, E. T. A., Page, S. E., Bocko, Y. E., \& Ifo, S. A. (2017). Age, extent and carbon storage of the central Congo Basin peatland complex. Nature. https://doi.org/10.1038/nature21048

Dumenford, D. (2006). Teologi dan Ekologi. Gunung Mulia.

Garcia-Ayllon, S. (2019). New strategies to improve co-management in enclosed coastal seas and wetlands subjected to complex environments: Socio-economic analysis applied to an international recovery success case study after an environmental crisis. Sustainability, 11(4), 1039. https://doi.org/10.3390/su11041039

Hansson, A., \& Dargusch, P. (2017). An estimate of the financial cost of peatland restoration in Indonesia. Case Studies in the Environment, 2(1), 1-8. https://doi.org/10.1525/cse.2017.000695

Hasan, M., \& Azis, M. (2018). Pembangunan Ekonomi \& Pemberdayaan Masyarakat. CV. Nur Lina.

M., O., Nursyamsi, D., Noor, M., Wahyunto, \& Segah, H. (2016). Peatland in Indonesia. In M. Osaki \& N. Tsuji (Eds.), Tropical peatland ecosystem (pp. 49-58). https://doi.org/10.1007/978-4-431-55681-7 
Martin, D. M. (2017). Ecological restoration should be redefined for the twenty-first century. Restoration Ecology, 25(5), 668-673. https://doi.org/10.1111/rec.12554

Masganti, Wahyunto, Ai Dariah, Nurhayati, \& Rachmiwati Yusuf. (2014). Characteristics and Potential Utilization of Degraded Peatlands in Riau Province. Jurnal Sumberdaya Lahan, 8(1), 59-66.

Miettinen, J., Shi, C., \& Liew, S. C. (2016). Land cover distribution in the peatlands of Peninsular Malaysia, Sumatra and Borneo in 2015 with changes since 1990. Global Ecology and Conservation, 6, 67-78. https://doi.org/10.1016/j.gecco.2016.02.004

Nasrul, B. (2015). Distribution and Potency of Peatlands for Agriculture in Bengkalis. Agroteknologi, 1, 1-7.

Neilson, J., \& Wright, J. (2017). The state and food security discourses of Indonesia: Feeding the bangsa. Geographical Research, 55(2), 131-143. https://doi.org/10.1111/17455871.12210

Page, S. E., \& Baird, A. J. (2016). Peatlands and global change: Response and resilience. Annual Review of Environment and Resources, 41, 35-57. https://doi.org/10.1146/annurevenviron-110615-085520

Permadi, B. (2019). Community Empowerment and Farmer Poverty Reduction in Developing Countries. Journal of Public Administration Studies. https://doi.org/10.21776/ub.jpas.2019.004.01.2

Pramudya, B., Jaswadi Purwanto, M. Y., \& Agus, F. (2020). The dynamics of biophysical characteristics and sustainability of peatland management under various types of land use. 12(1).

Roberts, D., \& Mattoo, A. (2018). Sustainable Agriculture-Enhancing environmental benefits, food nutritional quality and building crop resilience to abiotic and biotic stresses. Agriculture, 8(1). https://doi.org/10.3390/agriculture8010008

Sjögersten, S., Black, C. R., Evers, S., Hoyos-Santillan, J., Wright, E. L., \& Turner, B. L. (2014). Tropical wetlands: A missing link in the global carbon cycle? Global Biogeochemical Cycles. https://doi.org/10.1002/2014GB004844

Stephanie, E., Yule, C. M., Padield, R., O’Reilly, P., \& Varkkey, H. (2017). Keep wetland wet: the myth of sustainable development of tropical peatlands - Implication for policies and management. Global Change Biology, 23(2), 534-549. https://doi.org/10.1111/gcb.13422

Sulaiman, A. A., Sulaeman, Y., \& Minasny, B. (2019). A framework for the development of wetland for agricultural use in Indonesia. Resources, 8(34), 1-16. https://doi.org/10.3390/resources8010034.

Sulistyawan, B. S., Verweij, P. A., Boot, R. G. A., Purwanti, B., Rumbiak, W., Wattimena, M. C., Rahawarin, P., \& Adzan, G. (2018). Integrating participatory GIS into spatial planning regulation: the case of Merauke District, Papua, Indonesia. International Journal of the Commons, 12(1), 26-59. https://doi.org/10.18352/ijc.759

Sumarga, E., Hein, L., Hooijer, A., \& Vernimmen, R. (2016). Hydro-logical and economic effects of oil palm cultivation in Indonesian peatlands. Ecology and Society, 21(2), 52. https://doi.org/10.5751/ES-08490-210252

Swart, J. A. A., Zevenberg, J., Ho, P., Cortina, J., Reed, M., Derak, M., Vella, S., Zhao, H., \& van der Windt, H. J. (2018). Involving society in restoration and conservation. Restoration Ecology, 26(1), S3-S6. https://doi.org/10.1111/rec.12709

Syahza, A., Suwondo, Bakce, D., Nasrul, B., \& Mustofa, R. (2020). Utilization of peatlands based on local wisdom and community welfare in Riau Province, Indonesia. International 
Journal of Sustainable Development and Planning, 15(7), 1119-1126. https://doi.org/10.18280/IJSDP.150716

Thorburn, C. C., \& Kull, C. A. (2015). Peatlands and plantations in Sumatra, Indonesia: Complex realities for resource gover-nance, rural development and climate change mitigation. Asia Pacific View Point, 56(1), 153-168. https://doi.org/10.1111/apv. 12045

Turetsky, M. R., Benscoter, B., Page, S., Rein, G., van der Werf, G. R., \& Watts, A. . (2015). Global vulnerability of peatlands to fire and carbon loss. Nature Geoscience, 8, 11-14. https://doi.org/10.1038/ngeo2325

Uda, K. S., Hein, L., \& Sumarga, E. (2017). Towards sustainable management of Indonesian tropical peatlands. Wetlands Ecology and Management Volume, 25, 683-701. https://doi.org/10.1007/s11273-017-9544-0

Wahyunto, Ritung, S., \& Subagjo, H. (2003). Peta Luas Sebaran Lahan Gambut dan Kandungan Karbon di Pulau Sumatera / Map of Area of Peatland Distribution and Carbon Content in Sumatera, 1990-2002. Wetlands International - Indonesia Programme \& Wildlife Habitat Canada (WHC), 9. 